\title{
Evaluation of Maize (Zea mays L.) Genotypes for Morphological and Root Characters under Excessive Moisture Stress Condition
}

\author{
Satish Chandra Narayan'*, Manigopa Chakraborty', Krishna Prasad', \\ Savita Ekka ${ }^{2}$, Milan Kumar Chakravarty ${ }^{3}$, Veena Kumari Tudu', Mukesh Mahto', \\ Ravindra Kumar ${ }^{4}$, Rameswar Prasad $\mathrm{Sah}^{5}$ and Varsha Rani ${ }^{6}$ \\ ${ }^{1}$ Department of Genetics and Plant Breeding, ${ }^{2}$ Department of Plant Pathology, \\ ${ }^{3}$ Department of Entomology, ${ }^{4}$ Department of Horticulture, BAU, Ranchi, Jharkhand ,India \\ ${ }^{5}$ Division of Crop Improvement, NRRI, Cuttack, Odisha, India \\ ${ }^{6}$ Department of Crop Physiology, BAU,Kanke Ranchi, India
}

*Corresponding author

\section{Keywords}

Tasseling stage, Knee high stage, Flooding

Article Info

Accepted:

15 December 2019

Available Online:

20 January 2020

\section{A B S T R A C T}

Maize is highly productive crop if it is grown under optimal environmental and management conditions. Waterlogging, caused by contingent flooding, continuous rainfall and inadequate drainage or a high water table, is one of the most important constraints for maize production in Asia and many other parts of the world. In the present experiment 6 maize genotypes was studied under waterlogged condition for seven days inundation at three different growth stages viz, at the seedling stage (10 days after sowing), the knee high stage (30 days after sowing) and tasseling stage (50 days after sowing). Days to $50 \%$ anthesis (DT), Days to $50 \%$ silking (DS), number of dried leaves and number of brace roots increased but plant height, ear height, root fresh weight, root dry weight and root length were decreased under waterlogged condition.BAU-15-102 performed better than all other genotypes under waterlogged condition.

\section{Introduction}

Maize is the third most important crop in India after rice and wheat (Al-Swailem et al., 2005; Yadav et al., 2014). It is under cultivation across the globe, including tropical, subtropical and temperate regions, from sea level to $3000 \mathrm{~m}$ above sea level. The Composition per $100 \mathrm{~g}$ of edible portion of maize (dry) is Protein 11.1g, Fat $3.6 \mathrm{~g}$, Fibre $2.7 \mathrm{~g}$, Calories 342, Amino acids $1.78 \mathrm{mg}$, Carbohydrates $66.2 \mathrm{~g}$, Calcium $10 \mathrm{mg}$, Iron 
$2.3 \mathrm{mg}$, Carotene $90 \mathrm{ug}$, Vitamin C $0.12 \mathrm{mg}$ etc. (Gopalan et al., 2007). There are many theories depicting the specific origin of maize in Mesoamerica. Being a $\mathrm{C}_{4}$ plant, it is most productive in terms of food nutrients produced per unit land area, per unit of water transpired and per unit of time.

Among the various abiotic stresses, waterlogging, caused by contingent flooding, continuous rainfall and inadequate drainage or a high water table, is one of the most important constraints for maize production in Asia and many other parts of the world. In South Asia alone, more than $15 \%$ of the total maize growing area is affected by floods and water-logging problems (Rathore et al., 1997; Chen et al., 2014), resulting into production losses by $25-30 \%$ yearly.

Responses of plant to anoxia lead to changes at the molecular, biochemical, physiological, anatomical and morphological levels. The aerenchyma formation (Mano et al., 2006) in root cortex, stem hypertrophy and adventitious root aids for adaptation under to flooding stress. Excess moisture stress at knee-high stage, suppressed plant growth and development (stunted growth), considerable reduction in dry matter accumulation, transpiration, leaf area development, affected anthesis and silking, anthesis-silking interval (ASI) and eventually resulted poor grain formation and poor yield (Rathore et al., 1997). Waterlogging at early growth stages causes severe reductions in plant height, dry matter accumulation, and yield (Liu et al., 2010; Mukhtar et al., 1990; Rao and Li 2003). Maize is also very susceptible to waterlogging stress at an early vegetative stage (Mukhtar et al., 1990; Lone and Warsi 2009), but late vegetative and pollination stages are also very sensitive to waterlogging ( $\mathrm{Pal}$ and Varade 1984; Fausey et al., 1985; Kanwar and Sial 1988). When the plants undergone excessive moisture stress at different growth stage resulted into reduced plant growth and yield. Maize, when waterlogged, shows an increase in the number of nodes bearing adventitious roots, also termed nodal roots (Lone and Warsi 2009). Under waterlogged conditions, development of adventitious roots acts as a survival mechanism by anchoring the plants and thus avoiding lodging. The tips of adventitious roots and root hairs help plants to obtain oxygen dissolved in water (Grinieva et al., 1991; Mahal et al., 2000; Lizaso et al., 2001).

The present investigation aimed to study the effect of excess soil moisture stress on critical growth stages, i.e., seedling stage, knee height stage and taselling stage, affecting morphological and root attributes of maize genotypes to identifying resistant maize genotypes at the field level.

\section{Materials and Methods}

An experiment was conducted during kharif 2018 at the agricultural research farm, Birsa Agricultural University, Kanke, Ranchi. Seeds of 6 maize genotypes viz., BAU-15145, BAU-15-102, BAU-15-180, BAU-15-78 -1, BAU-15-122 and BAU-15-87, taken from the maize research project, were sown in maize research plot. The experiment was laid out in a randomized block design with two replications under normal fertilization. After sowing Atrazine @ 4 g/ L was sprayed to arrest the weed growth. Four manual weedings were carried out during crop period. Each plot was $1 \mathrm{~m}$ in length, row to row spacing $0.5 \mathrm{~m}$ and plant to plant spacing was $0.2 \mathrm{~m}$.Plastic sheets of 6 feet depth was laid out by the side of control plots to avoid the water seepage from the flooding treatment plots. Excess soil moisture stress was imposed by flooding the plots and maintaining the water level $10 \mathrm{~cm}$ above the soil surface for 7 days. The stress was imposed either at the seedling stage (10 days after sowing), the knee high 
stage (30 days after sowing) and tasseling stage (50 days after sowing) The excess water was drained out after 7days of flooding and later on plots were maintained at a normal level of soil moisture. Various parameters were recorded in normal and excess moisturestressed plants at the maturity of plants. Plants maintained under normal irrigation served as the control and others at three flooding time viz., the seedling stage (10 days after sowing TRT 1), the knee high stage (30 days after sowing, TRT 2) and tasseling stage (50 days after sowing TRT3) were treatment plots. Days to $50 \%$ anthesis (DT) was recorded in terms of number of days taken from the date of planting to the date when anthesis occurred in $50 \%$ of the plants. Similarly, days to ear emergence as 50\% silking (DS) were also recorded. The height of the plants was measured from the ground level to the apex of plant and the average was expressed as plant height in $\mathrm{cm}$. The ear height was measured from the ground level to the node where ear emerged on the stalk and the average was expressed as ear height in $\mathrm{cm}$. Total count of leaf emerged on the plants as leaf per plant (LPP) and number of dried leaf as number of dry leaf per plant(NDL). Representative whole plant along with roots and leaves were sun dried completely and weighed to get plant dry weight (PDW). Number of brace roots developed were counted and denoted as (NBR). Roots were taken out and washed thoroughly and weighed to take root fresh weight (RFW), and then dried and weighed to take readings of dry root weight (RDW). Length of roots were measured in $\mathrm{cm}$ and designated as (RL).

\section{Results and Discussion}

\section{Days to 50\% tasseling (DT)}

Days to $50 \%$ tasseling were higher at knee high stage for all the genotypes in comparison to both of other stages. Maximum \% increase was observed in BAU-15-87(15.9\%) and minimum in BAU-15-102(8.3\%) in TRT2. In TRT1, maximum was for BAU-15-145 and BAU-15-78 -1 (6.7\%), minimum for BAU15-180\& BAU-15-122 (4.4). In TRT3, highest was in BAU-15-87 (5.6\%) and lowest in BAU-15-102 \& BAU-15-122 (1.8\%). Data is presented in table 1 .

\section{Days to $50 \%$ silking (DS)}

In TRT1, maximum $\%$ increase in days to $50 \%$ silking(DS) was found in BAU-15-87 $(10.5 \%)$ and minimum in BAU-15-102(5\%). In TRT2 maximum \%increase was observed in BAU-15-87 (21.1\%) and minimum in BAU-15-102(10\%). But in TRT3 maximum was observed in BAU-15-87 (24.6\%) and minimum in BAU-15-102(13.3\%).Similarly Shah et al.,(2012) and Ren et al., (2014) has also observed that delay in days to $50 \%$ silking was highest at knee high stage. Data presented in table 2 .

\section{Ear height (EH)}

Maximum \% decrease of ear height was observed in BAU-15-145(20.3\%) and minimum in BAU-15-102 (8.7\%) when waterlogging was exposed at 30days after sowing (TRT2). In TRT1 highest \% decrease was found in BAU-15-145 (31.2\%) and lowest in BAU-15-102 (7\%). In TRT3 highest \%reduction was on served in BAU-15-180 $(4.8 \%)$ and lowest in BAU-15-102(1.95). Zhang et al., (2013) has also observed similar results in their experiments. Data are presented in table 3 .

\section{Plant height (PH)}

In TRT1maximum reduction in plant height was observed in BAU-15-78-1 (25\%) and minimum in BAU-15-102 (22\%). In TRT2 maximum height reduction was observed in BAU-15-122 \& BAU-15-87 (10.9\%) and 
minimum in BAU-15-102(8.9\%). In TRT3 not much difference was observed among the \%reduction for this trait (Table 4).

\section{Leaves per plant (LPP)}

Per cent reduction in number of leaves per plant was observed maximum in BAU-15-78 $-1(45.6 \%)$ and minimum in BAU-15$102(18.6 \%)$ in TRT1. This reduction was highest in BAU-15-180 (22.6\%) and least in BAU-15-102(6.2\%) in TRT2. In TRT3 highest reduction percentage was observed in BAU-15-145 (10.58\%) and lowest in BAU15-180 (7.58\%).Similar results are also observed by Shah et al., (2012).Data are presented in table 5 .

\section{Number of dry leaves (NDL)}

Waterlogging increased the number of dry leaves in all the three treatments for 7 days flooding in comparison to control plants. In TRT1 maximum \% increase was observed in BAU-15-122 (106.9\% 0 and minimum in BAU-15-102 (20\%). In TRT2 maximum increase percentage was observed in BAU-15$122(153 \%)$ and minimum in BAU-15-102 (51.6\%). In TRT3 maximum increase \% was observed in BAU-15-122 (184.6\%) and minimum in BAU-15-102(73.1\%). These findings are in congruence with the observation of Lizaso and Ritchie (1997) (Table 6).

\section{Plant dry weight (PDW)}

In TRT1 maximum reduction was observed in BAU-15-180 (30.6\%) and mimimum in BAU-15-102(12.5\%). In TRT2, maximum was observed in BAU-15-180 (34\%) and mimimum in BAU-15-102914.6\%). But in TRT3 maximum was observed in BAU-15180 (32.1\%)and mimimum in BAU-15$102(13.8 \%)$. This observation was also supported by the findings of Shah et al., (2011). Data are presented in table 7.

\section{Fresh root weight (FRW)}

In TRT1 maximum reduction was in BAU15-180 (12\%) and minimum in BAU-15102(4\%). In TRT2 maximum reduction found in BAU-15-78 -1 (22\%) band minimum in BAU-15-102(8.9\%). In TRT3, maximum reduction was recorded for BAU-15-78 -1 $(16.7 \%)$ and minimum in BAU-15-102 $(2.9 \%)$. These findings are in congruence with the findings of Li et al., (2018) who reported that waterlogging inhibited maize root and lateral root growth. Data are presented in table 8 .

\section{Dry root weight (DRW)}

In TRT1 maximum reduction was observed in BAU-15-78 -1 (26.9\%) and minimum in BAU-15-102(13.9\%). In TRT2 maximum reduction was found in BAU-15-78-1(36.7\%) and minimum in BAU-15-102(23.9\%). In TRT3 maximum reduction was found in BAU-15-78 -1(52.2\%) and minimum in BAU-15-102(39.9\%). Osman et al., (2013) has also found results similar to these findings. Data are presented in table 9.

\section{Number of brace roots (NBR)}

In TRT1maximum increase was observed in BAU-15-102(104.3\%) and minimum in BAU$15-180(23.5 \%)$.

In TRT2 maximum increase was observed in BAU-15-102(180.7\%) and minimum in BAU15-180 (47.2\%). TRT3maximum increase was observed in BAU-15-102(227.1\%) and minimum in BAU-15-87 (62.7\%). Zaidi et al., (2007) and Khaldun et al., (2017) has reported increase in brace root development is under waterlogged condition as a adaptation mechanism for anchorage and avoiding lodging. Data are presented in table 10. 
Table.1 Effect of waterlogging treatment on days to 50\% tasseling(DT) in days at different stages of maize genotypes. Values in parentheses indicate the percentage increase over the control

\begin{tabular}{|c|c|c|c|c|}
\hline Genotypes & Control & TRT1 & TRT2 & TRT3 \\
\hline BAU-15-145 & 52.5 & $56(6.7)$ & $59(12.4)$ & $54.5(3.8)$ \\
\hline BAU-15-102 & 54.5 & $57(4.6)$ & $59(8.3)$ & $55.5(1.8)$ \\
\hline BAU-15-180 & 56.5 & $59(4.4)$ & $65(15)$ & $58(2.7)$ \\
\hline BAU-15-78 -1 & 52.5 & $56(6.7)$ & $59(12.4)$ & $55(4.8)$ \\
\hline BAU-15-122 & 56.5 & $59(4.4)$ & $63(11.5)$ & $57.5(1.8)$ \\
\hline BAU-15-87 & 53.5 & $57(6.5)$ & $62(15.9)$ & $56.5(5.6)$ \\
\hline
\end{tabular}

Table.2 Effect of waterlogging treatment on days to 50\% silking(DS) in days at different stages of maize genotypes. Values in parentheses indicate the percentage increase over the control

\begin{tabular}{|c|c|c|c|c|}
\hline Genotypes & Control & TRT1 & TRT2 & TRT3 \\
\hline BAU-15-145 & 58 & $64(10.3)$ & $67(15.5)$ & $71(22.4)$ \\
\hline BAU-15-102 & 60 & $63(5)$ & $66(10)$ & $68(13.3)$ \\
\hline BAU-15-180 & 60 & $65(8.3)$ & $72(20)$ & $75(25)$ \\
\hline BAU-15-78 -1 & 58 & $63(8.6)$ & $68(17.2)$ & $71(22.4)$ \\
\hline BAU-15-122 & 61 & $66(8.2)$ & $70(14.8)$ & $74(21.3)$ \\
\hline BAU-15-87 & 57 & $63(10.5)$ & $69(21.1)$ & $71(24.6)$ \\
\hline
\end{tabular}

Table.3 Effect of waterlogging treatment on ear height(EH) in $\mathrm{cm}$ at different stages of maize genotypes. Values in parentheses indicate the percentage decrease over the control

\begin{tabular}{|c|c|c|c|c|}
\hline Genotypes & Control & TRT1 & TRT2 & TRT3 \\
\hline BAU-15-145 & 111.4 & $76.6(31.2)$ & $88.8(20.3)$ & $108.3(2.8)$ \\
\hline BAU-15-102 & 108.7 & $101(7))$ & $99.2(8.7)$ & $106.6(1.9)$ \\
\hline BAU-15-180 & 102.9 & $78.5(23.7)$ & $90.6(11.9)$ & $98(4.8)$ \\
\hline BAU-15-78 -1 & 103.7 & $78.3(24.5)$ & $90.4(12.8)$ & $101.6(2.1)$ \\
\hline BAU-15-122 & 118.6 & $88.3(25.6)$ & $100.4(15.3)$ & $116.1(2.1)$ \\
\hline BAU-15-87 & 92.2 & $73.4(20.4)$ & $79.8(13.4)$ & $88.5(4.0)$ \\
\hline
\end{tabular}

Table.4 Effect of waterlogging treatment on plant height $(\mathrm{PH})$ in $\mathrm{cm}$ at different stages of maize genotypes. Values in parentheses indicate the percentage decrease over the control

\begin{tabular}{|c|c|c|c|c|}
\hline Genotypes & Control & TRT1 & TRT2 & TRT3 \\
\hline BAU-15-145 & 210.8 & $162.3(23)$ & $191.1(9.3)$ & $209.2(0.8)$ \\
\hline BAU-15-102 & 213.4 & $166.4(22)$ & $194.4(8.9)$ & $211.7(0.8)$ \\
\hline BAU-15-180 & 246.7 & $187.4(24)$ & $220.5(10.6)$ & $245.0(0.7)$ \\
\hline BAU-15-78 -1 & 225.2 & $168.9(25)$ & $200.8(10.8)$ & $223.55(0.7)$ \\
\hline BAU-15-122 & 244.2 & $188(23)$ & $217.5(10.9)$ & $242.5(0.7)$ \\
\hline BAU-15-87 & 196.5 & $149.3(24)$ & $175.2(10.9)$ & $194.8(0.8)$ \\
\hline
\end{tabular}


Table.5 Effect of waterlogging treatment on leaves per plant, LPP(no.) at different stages of maize genotypes. Values in parentheses indicate the percentage decrease over the control

\begin{tabular}{|c|c|c|c|c|}
\hline Genotypes & Control & TRT1 & TRT2 & TRT3 \\
\hline BAU-15-145 & 13.8 & $9.3(32.5)$ & $11.8(14.5)$ & $12.3(10.8)$ \\
\hline BAU-15-102 & 16.1 & $13.1(18.6)$ & $15.1(6.2)$ & $14.8(8.4)$ \\
\hline BAU-15-180 & 13.5 & $8.1(39.6)$ & $10.5(22.6)$ & $12.5(7.8)$ \\
\hline BAU-15-78 -1 & 13.5 & $7.3(45.6)$ & $9.3(30.8)$ & $12.3(8.50)$ \\
\hline BAU-15-122 & 14.5 & $10.3(28.7)$ & $12.3(14.8)$ & $13.3(7.9)$ \\
\hline BAU-15-87 & 14.5 & $9.5(34.4)$ & $11.1(23.1)$ & $13.2(9.3)$ \\
\hline
\end{tabular}

Table.6 Effect of waterlogging treatment on number of dry leaves (NDL) at different stages of maize genotypes. Values in parentheses indicate the percentage increase over the control

\begin{tabular}{|c|c|c|c|c|}
\hline Genotypes & Control & TRT1 & TRT2 & TRT3 \\
\hline BAU-15-145 & 2.9 & $5.2(81.3)$ & $6.2(116.4)$ & $6.5(127.4)$ \\
\hline BAU-15-102 & 3.2 & $4.5(20)$ & $4.8(51.6)$ & $5.5(73.1)$ \\
\hline BAU-15-180 & 4.2 & $5.3(28.1)$ & $6.5(55.8)$ & $6.8(64.65)$ \\
\hline BAU-15-78 -1 & 2.5 & $4.8(93.3)$ & $5.7(108.1)$ & $6.5(161.0)$ \\
\hline BAU-15-122 & 2.2 & $4.5(106.9)$ & $5.5(153.0)$ & $6.2(184.6)$ \\
\hline BAU-15-87 & 2.5 & $4.5(80.5)$ & $5.5(120.8)$ & $5.5(120.8)$ \\
\hline
\end{tabular}

Table.7 Effect of waterlogging treatment on plant dry weight, PDW (gm) at different stages of maize genotypes. Values in parentheses indicate the percentage decrease over the control

\begin{tabular}{|c|c|c|c|c|}
\hline Genotypes & Control & TRT1 & TRT2 & TRT3 \\
\hline BAU-15-145 & 362.8 & $309.0(14.8)$ & $300.0(17.3)$ & $299.5(17.4)$ \\
\hline BAU-15-102 & 285.0 & $249.2(12.5)$ & $243.2(14.6)$ & $245.4(13.8)$ \\
\hline BAU-15-180 & 361.7 & $250.7(30.6)$ & $244.1(34)$ & $245.7(32.1)$ \\
\hline BAU-15-78 -1 & 355.8 & $278.8(21.6)$ & $274.1(25.2)$ & $277.3(22.0)$ \\
\hline BAU-15-122 & 244.8 & $204.1(16.6)$ & $199.9(18.3)$ & $203(17)$ \\
\hline BAU-15-87 & 354.1 & $288.1(18.6)$ & $278.7(21.2)$ & $284.3(19.7)$ \\
\hline
\end{tabular}

Table.8 Effect of waterlogging treatment on fresh root weight, FRW (gm) at different stages of maize genotypes. Values in parentheses indicate the percentage decrease over the control

\begin{tabular}{|c|c|c|c|c|}
\hline Genotypes & Control & TRT1 & TRT2 & TRT3 \\
\hline BAU-15-145 & 49.6 & $44.05(11.2)$ & $38.9(21.6)$ & $42(15.3)$ \\
\hline BAU-15-102 & 45.4 & $43.6(4)$ & $41.4(8.9)$ & $44.1(2.9)$ \\
\hline BAU-15-180 & 49.2 & $43.3(12.0)$ & $38.5(21.8)$ & $41.1(16.5)$ \\
\hline BAU-15-78 -1 & 49.0 & $44.0(10.2)$ & $38.2(22)$ & $40.8(16.7)$ \\
\hline BAU-15-122 & 48.55 & $45.7(5.9)$ & $39.9(17.8)$ & $42.5(12.5)$ \\
\hline BAU-15-87 & 51.625 & $49.1(4.8)$ & $44.1(14.5)$ & $46.7(9.5)$ \\
\hline
\end{tabular}


Table.9 Effect of waterlogging treatment on dry root weight, DRW (gm) at different stages of maize genotypes. Values in parentheses indicate the percentage decrease over the control

\begin{tabular}{|c|c|c|c|c|}
\hline Genotypes & Control & TRT1 & TRT2 & TRT3 \\
\hline BAU-15-145 & 15.6 & $11.8(24.1)$ & $10.4(33.4)$ & $8.0(48.2)$ \\
\hline BAU-15-102 & 14.4 & $12.4(13.9)$ & $10.8(23.9)$ & $8.7(39.9)$ \\
\hline BAU-15-180 & 15.3 & $11.3(25.6)$ & $9.9(35.1)$ & $7.6(50.2)$ \\
\hline BAU-15-78 -1 & 14.9 & $10.9(26.9)$ & $9.4(36.7)$ & $7.1(52.2)$ \\
\hline BAU-15-122 & 14.4 & $12.4(14.2)$ & $10.9(24.3)$ & $8.6(40.2)$ \\
\hline BAU-15-87 & 15.6 & $12.2(21.8)$ & $10.7(31.1)$ & $8.4(45.9)$ \\
\hline
\end{tabular}

Table.10 Effect of waterlogging treatment on number of brace roots (NBR) at different stages of maize genotypes. Values in parentheses indicate the percentage increase over the control

\begin{tabular}{|c|c|c|c|c|}
\hline Genotypes & Control & TRT1 & TRT2 & TRT3 \\
\hline BAU-15-145 & 14.9 & $25.45(70.8)$ & $33.5(124.8)$ & $37.5(151.7)$ \\
\hline BAU-15-102 & 14.0 & $28.6(104.3)$ & $39.3(180.7)$ & $45.8(227.1)$ \\
\hline BAU-15-180 & 18.1 & $22.35(23.5)$ & $28(54.7)$ & $31.5(74)$ \\
\hline BAU-15-78 -1 & 13.4 & $17.2(28.4)$ & $21.9(63.4)$ & $27.4(104.5)$ \\
\hline BAU-15-122 & 15.2 & $20.85(37.2)$ & $28.7(88.8)$ & $34.2(125)$ \\
\hline BAU-15-87 & 19.3 & $24.1(24.9)$ & $28.4(47.2)$ & $31.4(62.7)$ \\
\hline
\end{tabular}

Table.11 Effect of waterlogging treatment on root length(RL), in $\mathrm{cm}$ at different stages of maize genotypes. Values in parentheses indicate the percentage decrease over the control

\begin{tabular}{|c|c|c|c|c|}
\hline Genotypes & Control & TRT1 & TRT2 & TRT3 \\
\hline BAU-15-145 & 30.1 & $27.8(7.5)$ & $27.3(9.2)$ & $25.4(15.7)$ \\
\hline BAU-15-102 & 26.7 & $25.6(3.6)$ & $25.3(5.1)$ & $24.5(8.2)$ \\
\hline BAU-15-180 & 29.7 & $26.9(9.6)$ & $25.9(12.9)$ & $23.5(20.9)$ \\
\hline BAU-15-78 -1 & 25.7 & $23.3(9.3)$ & $21.3(17)$ & $19.4(24.4)$ \\
\hline BAU-15-122 & 16.3 & $14.2(13.3)$ & $14.9(8.5)$ & $13.0(20.1)$ \\
\hline BAU-15-87 & 31.3 & $28.5(9.2)$ & $27.2(13.2)$ & $24.9(20.5)$ \\
\hline
\end{tabular}

\section{Root length (RL)}

In TRT1 maximum $\mathrm{RL}$ reduction was observed in BAU-15-122 (13.3\%) and minimum in BAU-15-102(3.6\%). In TRT2 maximum reduction was found in BAU-15-87 $(13.2 \%)$ and minimum in BAU-15102(5.1\%). In TRT3 maximum reduction was found in BAU-15-87 (20.5\%) and minimum in BAU-15-102(8.2\%). These findings can be supported by the reports of Jensen et al., (1967). Data are presented in table 11.

\section{References}

Al- Swailem, A. M., Shehata, M.M., Shair, O.H., Sabaan, S.A., Al-Anazi, I.O. and Al- Shammari, T. A. 2005. An efficient method for identification and qualification of Genetic modification of local, improved and food products of maize in Saudi Arabia using PCR-based markers and real time PCR. Journal of Food, Agriculture and Environment. 3(2): $14-19$. 
Yadav V.K., Jat S.L. and Singh K.P. 2014. Popular Kheti, 2(4): 26-28.

Gopalan, C., Rama Sastri, B. V., \& Balasubramanian, S. 2007. Nutritive value of Indian foods. Hyderabad: National Institute of Nutrition (NIN), ICMR

Rathore, T. R., Warsi, M. Z. K., Lothrop, J. E. and Singh, N. N. 1997 Waterlogging problem for maizeproduction in Asian region. TAMNET News Letter 4: 1314.

Mano, Y., Omori, F., Takamizo, T., Kindiger, B., Mck, B. R. and Loaisiga, C.H. 2006).Variation for root aerenchyma formation in flooded and non-flooded maize and teosinte seedlings. Plant and Soil. 281: 269-279.

Mukhtar, S., Bakler, J.L., Kanwar, R.S. 1990. Maize growth as affected by excess soil water. Trans ASAE 33: 437-442

Lone, A.A. and Warsi, M.Z.K. 2009). Response of Maize (Zea mays L.) To Excess Soil Moisture (ESM) Tolerance at Different Stages of Life Cycle. Botany Research International 2 (3): 211-217.

Liu YZ, Tang B, Zheng YL, Ma KJ, Xu SZ, Qiu FZ, 2010. Screening methods for waterlogging tolerance at maize (Zea mays L.) seedling stage. Agrl Sci China 9(3): 362-369

Fausey, N. R., Van Toai, T. T. and McDonald, Jr. M. B. 1985. Response of ten corn cultivars to flooding. TRANSACTIONS of the ASAE 28(6):1794-1797.

Lone AA, Warsi MZK, 2009. Response of maize (Zea mays L.) to excess soil moisture (ESM) tolerance at different stages of life cycle. Bot Res Inter 2(3): 211-217

Grinieva, G.N., McMichael, B.L and Person, H. 1991. Physiological and morphological changes in maize plants under various flooding conditions, plant and their environment. Proceedings of ISSR Symposium, Uppsala, Sweden.2126 Aug, 1988.

Lizaso, J. I.; Melendez, L.M.; Ramirez, R. 2001. Early flooding of two cultivars of tropical maize. I. Shoot and root growth. J. Plant Nutr. 24: 979-995.

Shah, N.A., Srivastava, J.P., da Silva, J.AT., Shahi, J.P. 2012. Morphological and Yield Responses of Maize (Zea mays L.) Genotypes Subjected to Root Zone Excess Soil Moisture Stress. Plant Stress 6 (1), 59-72

Ren, B.; Zhang, J.; Li, X.; Fan, X.; Dong, S.; Liu, P.; Zhao, B. 2014.Effects of Waterlogging on the Yield and Growth of Summer Maize under Field Conditions. Can. J. Plant. Sci., (94), 23-31.

Zhang X, Tang B, Yu F, Li L, Wang M, Xuea Y, Zhang Z, Yan J, Yue B, Zheng Y, Fazhan QF, 2013. Identification of major QTL for waterlogging tolerance using genome-wide association and linkage mapping of maize seedlings. Plant Mol Biol Rep, 31(3): 594-606

Lizaso, J. I. and Ritchie, J. T 1997. Maize shoot and root response to root zone saturation during vegetative growth. Agronomy Journal 89: 125-134.

Li, W., Mo, W., Ashraf, U., LI, G.,Wen, T.,Abrar., M., Gao, L., Liu, J.,Hu, J. 2018. Evaluation of physiological indices of waterlogging tolerance of different Maize varieties in South China. Applied Ecology and Environment Research 16(2): 20592072.

Osman, K.A., Tang, B., Wang, Y., Chen, J., Yu, F., Li, L., 2013. Dynamic QTL analysis and candidate gene mapping for waterlogging tolerance at maize seedling stage. PLoS ONE 8(11): e79305. doi:10.1371/ journal. pone.0079305

Zaidi, P.H., P. Maniselvan, P., Yadav, P., 
Singh, A.K., Sultana, R., Dureja,P., Singh, R.P., Srinivasan, G. 2007). Stress adaptive changes in tropical Maize (Zea mays L.) under excessive soil moisture stress. Maydica (52): 159-171.

Khaldun, A. B.M., Matin, M.Q. I., ZonayedUll-Noor, A.K.M., Alam, M.K., Hoque, M.E., and Rohman, M.M.
2017.Evaluation of waterlogged tolerant maize (Zea mays L) hybrids in Bangladesh. Eco-friendly Agril. J. 10(05):71-75.

Jensen, C.R., L.H. Stolzy and J. Letey, 1967. Tracer studies of oxygen diffusion through roots of barley, corn and rice. Soil Sci., (103): 23.

\section{How to cite this article:}

Satish Chandra Narayan, Manigopa Chakraborty, Krishna Prasad, Savita Ekka, Milan Kumar Chakravarty, Veena Kumari Tudu, Mukesh Mahto, Ravindra Kumar and Rameswar Prasad Sah. 2020. Evaluation of Maize (Zea mays L.) Genotypes for Morphological and Root Characters under Excessive Moisture Stress Condition. Int.J.Curr.Microbiol.App.Sci. 9(01): 839-847. doi: https://doi.org/10.20546/ijcmas.2020.901.092 